\title{
Determinants of Business Exits in Australia
}

\author{
Yongqiang Li, Anona Armstrong and Andrew Clarke \\ Victoria University, Australia
}

\begin{abstract}
The annually increasing firm exits have significant financial, legal and social impacts on productivity, employment and economic growth in Australia. However, evidence of the impacts of firm exits is sparse. This paper undertakes a first-ever study that empirically investigates the determinants and their impacts on firm churn. This paper is innovative to the literature in four aspects: (1) Local Region Areas (LGAs) data, rarely available in other countries, has been used for the analysis; (2) using LGAs as the basic analytical unit is able to eliminate the heterogeneity problems encountered by other studies which are based on national and cross-national data; (3) panel data modelling techniques identify robust evidence; (4) systematic statistical tests guarantees the robustness of the results. The dataset, provided by Australia Bureau of Statistics, include 3462 observations of 577 Local Government Areas (LGAs) during 2004-2009. The research identifies variables positively and negatively affecting the exits and finds that size matters in determining business exits. The last section concludes with a discussion of limitations and future research directions.
\end{abstract}

\section{Keywords}

Business exits, determinants, panel data, Australia

\section{Introduction}

Most research has been devoted to analysing factors that determines business entries and entrepreneurial engagement. Less has been done to question what drives entrepreneurs toward business exits [11]. This is particularly true in Australia. The number of business exits in Australia as a result of mining boom has been increasing in the past five years and evidence shows that this trend is continue to growth at an accelerated rate [5]. Thus, this paper empirically analyses the impacts of factors that drive business exits in Australian Local Government Areas

(LGAs).

Copyright (C) 200x Victoria University. This document has been published as part of the Journal of Business Systems, Governance and Ethics in both online and print formats. Educational and non-profit institutions are granted a nonexclusive licence to utilise this document in whole or in part for personal or classroom use without fee, provided that correct attribution and citation are made and this copyright statement is reproduced. Any other usage is prohibited without the express permission of the publisher.

\section{Business exit}

Business exit is defined as the number of businesses deregistered in the ABS Registrar. According to ABS [1], business exits are continuously increasing over the past five years and this trend is predicted to continue. Though the 
exits are diversified in different regions, it is apparent that in the most populated regions, the exits are far higher.

Business exits have significant impacts on business dynamisms, employment, innovation, productivity and innovation. The reality is there is not much empirical work done to provide solid evidence. This research intends to start the discussion around this area and fill in the gap.

\section{Definition of LGAs}

ABS [2] defines LGAs as follows

'A Local Government Area (LGA) is a geographical area under the responsibility of an incorporated local government council, or an incorporated Indigenous government council. The LGAs in Australia collectively cover only a part of Australia. The main areas not covered by LGAs are northern parts of South Australia, a large part of the Northern Territory, the western division of New South Wales, all of the Australian Capital Territory and the Other Territories'.

\section{Identified research gap and how this paper fills the gap}

The extant research leaves the following gaps: (1) panel-data analysis based on pure regional data is not available in most of the countries; (2) previous research only focuses on factors which are partially impact of exits due to the availability of the data. This paper is innovative to the literature in four aspects: (1) Local Region Areas (LGAs) data, rarely available in other countries, has been used for the analysis; (2) using LGAs as the basic analytical unit is able to eliminate the heterogeneity problems encountered by other studies which are based on national and crossnational data; (3) panel data modelling techniques identify robust evidence; (4) systematic statistical tests guarantees the robustness of the results.

The perceived gap in the knowledge about small business exits and research in small businesses, to be filled by this paper, leads to the following research questions.

\section{What are the determinants of business exits in regional Australia?}

The rest of the paper proceeds as follows: Section 2 reviews the literature and identifies factors pertinent to firm churn; Section 3 provides details of the sample, data and methodology; Results are discussed in Section 4; Section 5 concludes with some policy recommendations.

\section{Literature review}

Exits can be voluntary or involuntary. Voluntary exits can be a function of alternative business options, i.e. to earn wage and salary, to invest, or to live on pension. Involuntary exits can be a function of unemployment and population, business entries, entries of businesses employing, entries of businesses not employing. In addition, the exits may be determined by industry and regional characteristics (). Thus, the literature on the determination of regional business exits can be divided into three strands: the macroeconomic factors, other competing income sources, and industry characteristics.

\section{The impact of churn on the regional economy}

There is no consensus in the academia with regards to the impact of economic churn on employment. One stream of researchers for the positive impacts identified empirical evidence 
from the Schumpeterian idea of creative destruction. However, they do admit that the employment impact of new firms is not immediate. This line of thinking further argued that the replacement of inefficient and unproductive firms or the expansion of the current plants may potentially associate with increasing demand of labour [10]. The other stream, which is against the positive impacts, argued that higher business churns associates with higher earnings volatility and greater job uncertainties [6].

It is self-evident that negative impacts including decline in productivity, employment, economic growth are all associated with potential social costs, while positive impacts including the increasing dynamism, competition and innovation boost economic growth. Well-designed government intervention can minimise such losses and/or maximise economic gains.

The direct link between SME churn and economic growth has not been well researched in the literature [10]. Andre Stel and Storey [12] find that total entrepreneurial activities influences GDP growth. It follows that if churn has a positive impact on productivity and entrepreneurship, it would positively influence the economic growth in the long run.

\section{Macro-level factors and exits}

Flynn [7] empirically tested the US cross-sectional data of the manufacturing sector and found that low income fosters exit. In Flynn's model, exit is defined as the gross number of firms that have exited from an industry during the period 1978 to 1984 [7]. However, he admitted that the empirical test against the widely accepted, whilst barely tested, significance of exits to the competitive models is mainly hampered by the availability of data. And Flynn's study suffers from aggregating the firm-level data to industry level data without given consideration to the heterogeneity of the firms.

Another macro-level factor identified in the previous research is unemployment, or employment [10]. Measuring the relationship between unemployment and churn is complex because data for the numbers of jobs created and destroyed will include the employing of new entrants as well as increased employment from the growth of existing plants. And high business exits are always associated with high unemployment [6].

The role of working population, normally defined as population at the age of $15-65$, is another factor affecting the exits. Love used a UK dataset covering 64 British countries over the period 1980-1988 and found that population is positively determining the exits in UK [8].

\section{Competing income sources and exits}

Apesteguia and Ballester extend the behaviour science research on human preference given consideration to the reference of peers [4]. Among various options, Wages \& salaries income, own unincorporated business income, investment income, superannuation income are alternatives to becoming an entrepreneur. Thus they are important factors to be considered.

\section{Industry and regional factors}

Total number of businesses operating in the region indicates competition and dynamism. Flynn and proceeding research identified that the total number of businesses within the industry is an positive factor affecting the exits $[7 ; 10]$. 
Business entries in the region are a critical factor determining the exits in that a large number of the new entries become sources of exits $[6 ; 10]$. Anyadike-Danes et. al. added to this argument that both business entries and business entries rates are pertinent to business exits [3].

Overall, theoretical and empirical work on exit is sparse. Studies focus more on the dynamic aspects of entry and exits, partially due to the availability of the data, and partially due to the research objectives [7]. Most of the evidence gathered is from the analysis of cross-section data, which is largely generated on an aggregated basis. This research attempts to fill such gaps.

\section{Sample, data and methodology}

\section{Sample and data}

The dataset is provided by Australia Bureau of Statistics. It includes 3462 observations of 577 Local Government Areas (LGAs) during 2004-2009. This study looks at the exits determination of non-employing businesses, micro-businesses and comparatively larger businesses.

Exits are defined as counts of trading businesses as at June in each reference year. Exits of nonemploying business are defined as counts of trading businesses as at June in each reference year which are not employing people. Exits of employing business are defined as counts of trading businesses as at June in each reference year which are employing people. All the exits data are from the ABS business Register. The other dependent variables follow the ABS definition [1], including average income, population, wages \& salaries income, own unincorporated business income, investment income, superannuation income, non-employing businesses, number of business employing one-to-four, number of business employing five or more, entries of nonemploying business, entries of employing business.

\section{Models}

The relationship between exits and its determinants can be mathematically put as follow

$$
y_{i, t}=f\left(x_{i, t}\right)+u_{i, t} \text {. }
$$

, where yi,t is a vector of dependent variables, consisted by total exits, exits of non-employing businesses and exits of employing businesses, $x i, t$ is a vector of exogenous variables; ui,t is the error term. Index i denotes panels, or LGAs here; $t$ denotes year.

The model can be specified in four explicit forms in Eq. (2)-(5).

$$
\begin{gathered}
\mathrm{y}_{\mathrm{i}, \mathrm{t}}=\alpha_{\mathrm{i}}+\beta \mathrm{x}_{\mathrm{i}, \mathrm{t}}+\mathrm{u}_{\mathrm{i}, \mathrm{t}} . \\
\mathrm{y}_{\mathrm{i}, \mathrm{t}}=\beta \mathrm{x}_{\mathrm{i}, \mathrm{t}}+\lambda_{\mathrm{t}}+\xi_{\mathrm{i}}+\mathrm{u}_{\mathrm{i}, \mathrm{t}} . \\
\mathrm{y}_{\mathrm{i}, \mathrm{t}}=\alpha+\beta \mathrm{x}_{\mathrm{i}, \mathrm{t}}+\mathrm{u}_{\mathrm{i}, \mathrm{t}} . \\
\mathrm{y}_{\mathrm{i}, \mathrm{t}}=\alpha+\beta_{1} \mathrm{x}_{\mathrm{i}, \mathrm{t}}+\beta_{2} \mathrm{w}_{\mathrm{i}, \mathrm{t}}+\mathrm{u}_{\mathrm{i}, \mathrm{t}} .
\end{gathered}
$$

, where $\alpha \mathrm{i}$ is the intercept; $\beta$ is a vector of coefficients to be estimated; $\lambda_{\mathrm{t}}$ is the time (year); $\xi_{\mathrm{i}}$ is fixed effect and is the LGA fixed effect; ui,t is the error term; $\alpha$ is the average exits for the entire population; $\beta_{1}$ is the vector of coefficients to be estimated for exogenous variables; $w_{i, t}$ is the vector of instruments, including number of business by industry by region by year.

Eq. (2) is using Ordinary Least Squares (OLS) estimator based on cross-sectional data, controlling year and clustering LGAs. Eq.(3) and Eq. (4) is the fixed- and random- effect model respectively based on panel data (Stock and Watson 2009). Eq. (5) is the instrument variable (IV) model based on panel data. The number of businesses within each industry is used as 
instruments ${ }^{9}$. Eq. (5) has also been estimated by using Generalized Methods of Moments (GMM) as the estimator.

In order to obtain robust results, all the models applied cluster analysis to minimise the heterogeneity among banks in different countries. In addition, robust option has been selected to correct heterogeneity.

The STATA 11.2 software is used to empirically specify the above models. Recently release XTIVREG2 package is couple GMM and fixed effect together for IV models using panel data.

\section{Results}

\section{Model selection and robustness tests}

Though OLS produces higher $\mathrm{R}^{2}$, panel data based models are preferred as they are able to capture both the 'between' and 'within' panel effects. Thus OLS can be used as a baseline model for comparison purpose. The Hausman Test shows that random effect models are better than fixed effect models in specifying the models respectively.

It is widely acknowledged that traditional models, including fixed- and random effect models suffer from three problems, namely omitted variable bias, measurement error and selection bias. The remedy to these problems is to use Instrument Variable (IV) modelling. Comparatively, IV models with GMM estimator produces more robust results at the cost of efficiency [13].

There are two main additional tests for IV models, one is to test whether the instrument variable is an instrument; the other is to test whether the model is under-identified, weak- identified, or over-identified. A valid instrument must satisfy two conditions, one is instrument relevance, and the other is instrument exogeneity. The former condition is proven to be valid from the Pearson correlation coefficients tests ${ }^{10}$. The later condition is examined in STATA (using 'orthog' option) and proven to be valid too. First stage $F$ values all shown to be significant, meaning that there is no weak instrument problem in all the specifications [9].

The under-identification test here adopts the Kleibergen-Paap rk LM statistic, which is automatically report in STATA 11.2 if 'xtivreg2' package is used. All the results reject the null hypothesis that each of the models is under-identified. The weak-identification test adopts the Cragg-Donald Wald F statistic and the results rejected the null hypothesis that the model is weakidentified. The over-identification test adopts Hansen J-Statistics and all the results were not able to reject the null hypothesis at 5\% significant level, meaning that the model is not over-identified. Other robustness tests, such as multi-collinearity and heterosckedasticity, have been corrected by using robust estimators in STATA. Thus the IV-GMM model is selected as the most appropriate model for the given dataset.

\footnotetext{
${ }^{9}$ The industry of personal is dropped in the computation due to multi-collinearity. For the sake of brevity, the process of the instruments selection is omitted here, but is available upon request.

${ }^{10}$ Test results are available upon request.
} 


\section{Summary of results}

For total business exits within a region, on average, average income is negatively contributing to the business exits. $\$ 1$ million increase in average income would result in 1330 less business exits, meaning that the more affluent the region is, the less likely businesses would exit. The coefficient of wages \& salaries income is statistically significantly negative, though an increase of $\$ 1$ million in wages \& salaries income is incurring 0.258 exits, noted that the base for wages \& salaries income is larger than average income.

The coefficient of investment income is statistically significant and positive. An increase of $\$ 1$ million in investment income leads to 0.367 more exits. The coefficient of superannuation income is statistically significant and negative. An increase of $\$ 1$ million in superannuation income leads to a decline of 1.29 exits. Number of businesses employing five or more people has a statistically significant and positive impact on exit, meaning that one increase in businesses employing five or more people resulted in 0.427 increases in business exits. The new entries of employing businesses are statistically significant and positive. One increase of the new entry that employs people leads to 0.445 increases in business exits. The rest of the variables are not statistically significant.

The determination of the exits of employing businesses follows similar statistical relationships for most of the variables, though the magnitudes of these variables are larger than those determined in the 'total exits' model. Using the same data and procedure, a few more variables become statistically significant, including number of non-employing businesses, number of businesses employing one to four people, and entries of non-employing businesses. Number of nonemploying businesses has a negative impact on business exit, specifically, one increase in nonemploying business leads to 0.129 less exits of employing businesses. Number of businesses employing one to four people has a negative impact on exits of employing businesses, and one increase of business employing one to four people lead to 0.262 declines of business exits. Entries of employing business have a positive impact and one increase in the entries of non-employing businesses leads to 0.472 more exits. 
Table 1 Summary of results

\begin{tabular}{|c|c|c|c|}
\hline Dependent variable & Exits & $\begin{array}{l}\text { Exits of non- } \\
\text { employing } \\
\text { business }\end{array}$ & $\begin{array}{l}\text { Exits of } \\
\text { employing } \\
\text { business }\end{array}$ \\
\hline average income & $-1330 * *$ & $1568^{* *}$ & $-2969 * * *$ \\
\hline unemployment & -0.0102 & 0.0155 & -0.0115 \\
\hline population & 0.00313 & -0.00101 & 0.00241 \\
\hline $\begin{array}{l}\text { wages \& salaries } \\
\text { income }\end{array}$ & $-0.258^{*}$ & $0.484 * * *$ & $-0.741 * * *$ \\
\hline $\begin{array}{l}\text { own unincorporated } \\
\text { business income }\end{array}$ & 0.265 & -0.552 & 0.646 \\
\hline investment income & $0.367 * *$ & $-0.624 * *$ & $0.977 * * *$ \\
\hline $\begin{array}{l}\text { Superannuation } \\
\text { income }\end{array}$ & $-1.29 *$ & $3.34 * * *$ & $-4.04 * * *$ \\
\hline $\begin{array}{l}\text { non-employing } \\
\text { businesses }\end{array}$ & 0.0158 & $0.1 *$ & $-0.129 *$ \\
\hline $\begin{array}{l}\text { no. of business } \\
\text { employing one-to-four }\end{array}$ & 0.0632 & $0.299 * * *$ & $-0.262 * *$ \\
\hline $\begin{array}{l}\text { no. of business } \\
\text { employing five or } \\
\text { above }\end{array}$ & $0.427 * * *$ & -0.157 & $0.621 * *$ \\
\hline $\begin{array}{l}\text { entries of non- } \\
\text { employing business }\end{array}$ & 0.0657 & $-0.303 * * *$ & $0.472 * * *$ \\
\hline $\begin{array}{l}\text { entries of employing } \\
\text { business }\end{array}$ & $0.445 * * *$ & $-0.624 * * *$ & $1.18 * * *$ \\
\hline
\end{tabular}

legend: $* \mathrm{p}<0.05 ; * * \mathrm{p}<0.01 ; * * * \mathrm{p}<0.001$

\section{Conclusion}

This paper intends to identify the factors determining the business exits in regional Australia through empirically testing the impact of each determinant on the number of business exits. The econometric models yields answers to the research question, as follows

Determinants for the total number of business exits are average income, wages $\&$ salaries income, investment income, superannuation income, number of businesses employing five or above, and number of entries of employing business, among which investment income, number of businesses employing five or more people and entries of employing businesses are positive determinants; whilst average income, wages \& salaries income, and superannuation income are negative determinants.

Determinants for the total number of exits of business not employing people are average income, wages \& salaries income, investment income, superannuation income, number of non-employing businesses, number of businesses employing one to four people, number of entries of both nonemploying and employing business, among which average income, wages \& salaries income, superannuation income, number of non-employing businesses, and number of businesses employing one to four people are positive determinants; whilst investment income, and number of entries of both non-employing and employing business are negative determinants. 
Determinants for the total number of exits of businesses employing people are average income, wages \& salaries income, investment income, superannuation income, number of non-employing businesses, number of businesses employing both one to four and five or above, and number of entries of both non-employing and employing business, among which investment income, number of non-employing businesses, number of businesses employing both one-to-four five or more people and entries of both non-employing and employing businesses are positive determinants; whilst average income, wages \& salaries income, and superannuation income are negative determinants.

The paper is subjected to two limitations, (1) though this paper tries to identify a whole list of exits determinants, it is only able to identify the determinants which are available in the database; (2) using the absolute number of exits as the only indicator of business exits may not be able to capture the whole story.

Future research can include firm level data to provide a systematic view of business exits. Future research can focus more on the following aspects: (1) values of more variables, in particular size of the business, should be collected and included in the analysis; (2) the research should look indepth to the fundamental issues of business exits and their potential impacts, i.e. efficiency, employment, regional economic growth, innovation and productivity.

\section{References}

[1] (ABS) Australian Bureau of Statistics (2010). Counts of Australia Businesses, including Entries and Exits, Jun 2007 to Jun 2009. Cat. No. 8165.0.

[2] ABS (2011). Census Dictionary, Cat. no. 2901.0 A. B. o. Statistics, Australian Bureau of Statistics.

[3] Anyadike-Danes, M., M. Hart, Maureen O'R. (2005). "“Watch that Space! The County Hierarchy in Firm Births and Deaths in the UK, 1980-1999"." Small Business Economics 25(3): 273-292.

[4] Apesteguia, J. and M. A. Ballester (2009). "A Theory of Reference-Dependent Behavior." Economic Theory 40(3): 427-455.

[5] Association, A. L. G. (2011). State of the Regions: 2011-2012, National Economics.

[6] Comin, D., L. Groshen, Robin, B. (2006). Turbulent firms, turbulent wages. Federal Reserve Bank of New York Staff Reports. No. 238,unpublished.

[7] Flynn, J. E. (1991). "The Determinants of Exit in an Open Economy." Small Business Economics 3(3): 225-232.

[8] Love, J. H. (1996). "The determinants of variations in exit rates." Empirica 23(1): 107-118.

[9] Stock, J. H. and M. W. Watson (2008). Introduction to econometrics : brief edition. Boston, Pearson/Addison Wesley.

[10] Robinson, C., B. O'Leary, Ricon, A. (2006). "Business start-ups, closures and economic churn: a review of the literature". UK, DTI.

[11] Wennberg, K., J. Wiklund, Dawn R. and Cardon, Melissa, S. (2010). "Reconceptualizing entrepreneurial exit: Divergent exit routes and their drivers." Journal of Business Venturing 25(4): 361375.

[12] André Stel, D. Storey and A. Thurik (2007). "The Effect of Business Regulations on Nascent and Young Business Entrepreneurship," Small Business Economics, Springer, vol. 28(2), pages 171-186, March.

[13] Drukker, D. (2010). "An Introduction to GMM Estimation Using STATA", German STATA Users' Group Meeting, unpublished. 